\title{
Serum enzymes in diseases of the thyroid gland ${ }^{1}$
}

\author{
P. D. GRIFFITHS \\ From the Harlow Group of Hospitals
}

SYNOPSIS Serum enzyme assays have been carried out in 66 patients suffering from diseases of the thyroid gland. Sixty per cent. of the hypothyroid patients had increased levels of aldolase and $\overline{0}$ glutamic oxaloacetic transaminase, and $90 \%$ had high activities of creatine kinase. The significance $\vec{\infty}$ of these findings, especially with regard to creatine kinase, is discussed.

In the course of an investigation into the potential value of assay of serum creatine kinase activity in clinical medicine, a specimen of serum submitted to the laboratory for determination of the cholesterol level was included also in a batch of creatine kinase assays. A high level of the enzyme's activity was demonstrated, and this result was subsequently confirmed on a further specimen from this patient, who proved to be a case of Hashimoto's disease. This finding prompted further study, and a preliminary investigation suggested that at least $60 \%$ of hypothyroid patients had raised levels of creatine kinase (Griffiths, 1963). A more extensive study was undertaken in which 66 patients with diseases of the thyroid gland were tested for serum activities of creatine kinase (ATP:creatine phosphotransferase), and, in many cases, transaminases (aminotransferases) and aldolase also.

\section{METHODS}

SUBJECTS The subjects were random patients presenting with thyroid disease. The diagnosis, made by the clinician in charge of the case, was supported by radioactive iodine studies and/or serum protein-bound iodine levels.

SERUM ASSAYS Serum was separated from venous samples of blood within two hours of shedding and stored at $-20^{\circ} \mathrm{C}$. when assays could not be performed immediately. Transaminase and aldolase estimations were not carried out on haemolysed samples because of potential leakage of these enzymes from red cells. As creatine kinase is present in negligible quantities in the human red cell (Solvonuk, McRae, and Collier. 1956), this assay is unaffected by haemolysed sera. With the exception of the transaminases for which the familiar KarmenWróblewski units have been retained, the results are expressed in International units.

Received for publication 23 March 1965.

${ }^{1}$ This paper is based on work published in a thesis approved for the degree of M.D. by the University of London.
1 Transaminases Glutamic oxaloacetic and glutamic $\circ$ pyruvic transaminases were estimated by a modification of the colorimetric procedure of Reitman and Frankel $(s)$ (1957), using reagents supplied by Messrs. Boehringer in $\mathbb{D}$ the form of a test kit.

2 Aldolase A modification of the spectrophotometric technique of Bruns (1954) was adopted, the reagents being supplied as a test kit by Messrs. Boehringer.

3 Creatine kinase The reverse reaction, in which $\vec{\mathscr{}}$ creatine and adenosine triphosphate are formed under the of influence of the enzyme from phosphorylcreatine and adenosine diphosphate, was employed. The method, which depends on the measurement of the creatine formed by means of the $\alpha$-naphthol-diacetyl reaction (Ennor and Rosenberg, 1954), has been described fully elsewhere (Griffiths, 1965).

\section{RESULTS}

The results of the creatine kinase assays in 66 patients with diseases of the thyroid gland and three patients with hypopituitarism are shown in Figure 1. The hypothyroid cases have been separated into spontaneous myxoedema, Hashimoto's disease, and myxoedema consequent upon radioactive iodine therapy for thyrotoxicosis. In all but four of the $\mathbf{3 9}$ hypothyroid patients elevated serum levels of creatine kinase were demonstrated. The 30 other $\frac{D}{0}$ patients, cases of treated myxoedema, of simple goitre, thyrotoxicosis, and hypopituitarism all had $\sigma$ normal levels.

Figure 2 shows the percentage of hypothyroid patients whose serum betrayed abnormal enzyme $c$ activities. Apart from one patient with a marginal level of 35 Karmen-Wróblewski units, all had normal levels of glutamic pyruvic transaminase. Approximately $60 \%$ had elevated levels of aldolase and glutamic oxaloacetic transaminase, whereas $90 \%$ had abnormal creatine kinase activities, the majority having levels between 100 and 300 units, although some were much higher. 


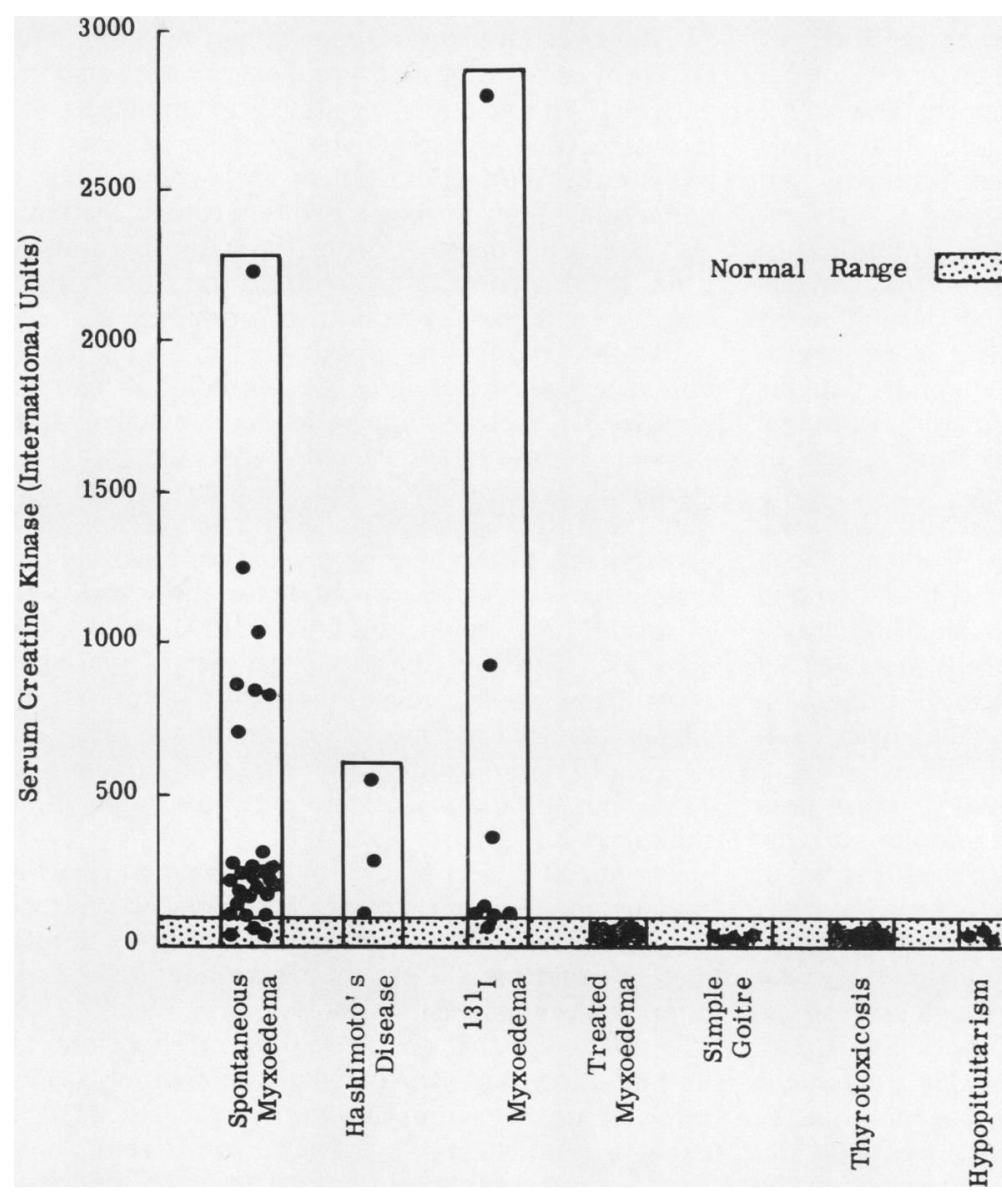

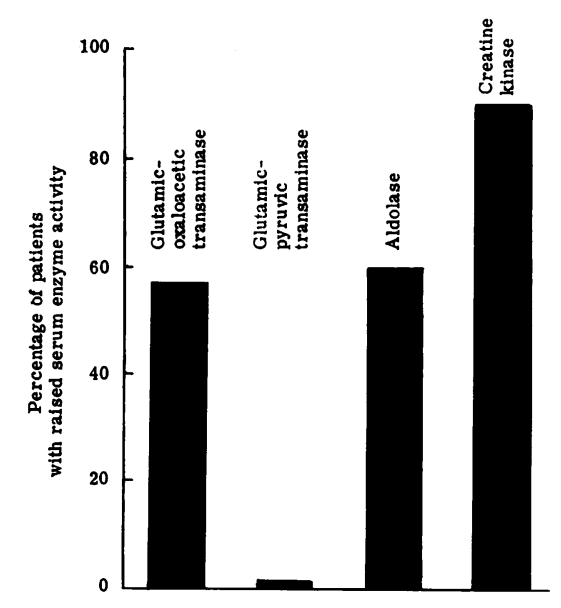

FIG. 2. Percentage of patients with elevated enzyme activities in case of hypothyroidism.
FIG. 1. Serum creatine kinase activity in thyroid disease.

Abnormal serum enzyme activities have been recorded before in patients with hypothyroidism. Vogliazzo, Viale, and Borney (1960b) had noted a small increase in glutamic oxaloacetic activity in three out of 10 cases of endemic cretinism, an observation in agreement with the findings of Della Santa (1962). During a study of 880 patients to assess the clinical significance of serum aldolase determinations, Sibley and Fleisher (1954) had noted abnormal activities in four out of five patients with myxoedema. Vogliazzo, Borney, and Gheis (1960a) found raised serum aldolase levels in all 10 of their patients with cretinism.

On the other hand, Lieberthal, Benson, and Klitgaard (1963) found that thyrotoxic patients had increased levels of serum malate dehydrogenase and hypothyroid patients demonstrated even higher activities of this enzyme.

In the case of creatine kinase, Graig and Ross 
(1963) recorded abnormal serum levels in 10 out of 15 patients with hypothyroidism, but found normal levels in other diseases of the thyroid gland. All eight of Saito, Hibi, Kawazura, and Fukuyama's (1963) child patients (seven were cretins) had increased activity of this serum enzyme.

One effect of substitution therapy is a rapid return to normal serum enzyme levels. Five of the patients of Saito et al. (1963) demonstrated normal levels within three weeks of commencement of treatment, and in the series reported in this study most patients had normal levels within a month and, with one exception, always by the time they were judged as being clinically euthyroid.

The cause of the raised enzyme activities in hypothyroidism presents an intriguing problem. Della Santa (1963) suggested that impaired liver function was the cause of the increased oxaloacetic transaminase, but he found only small increases in pyruvic transaminase. Aldolase also is present in relatively high concentration in the liver, and abnormal serum levels are seen following liver damage, but Vogliazzo et al. (1960a) found normal levels of lactate dehydrogenase, another enzyme usually showing increased activity in liver disease, in all but one of their patients. The normal pyruvic transaminase levels of this study, and the high levels of creatine kinase, an enzyme whose serum activity is unaffected by liver disease, both weigh against this hypothesis.

Bertolini and Quarto di Palo (1958) studied the creatine kinase activity of heart homogenates in the rat, and they found that both increased and decreased thyroxine secretion led to a decrease in the enzyme activity of the homogenates, and an implication is, although this was not studied, that the serum levels of the enzyme would increase both in hypo-and hyperthyroidism as was observed with malate dehydrogenase (vide supra). However, in man, it has been demonstrated that only the hypothyroid patients have increased serum creatine kinase activity.

It has been generally accepted that increased serum levels of an enzyme are due to a release of it from damaged cells of a tissue rich in the enzyme. In this instance a leakage from skeletal or cardiac muscle or both would be postulated. In hypothyroidism, it is well known that there is excessive retention of creatine, a fact that can be demonstrated by the creatine tolerance test. In muscular dystrophies, where there are also high levels of creatine kinase in the serum (e.g., Ebashi, Toyokura, Momoi, and Sugita, 1959), there is a creatinuria. It is difficult to conceive a hypothesis which will link these findings satisfactorily.

A possible relationship between hypothyroidism and muscular dystrophy was explored by Saito et al: (1963) by administering thyroid extract to dystrophy $\overrightarrow{\vec{F}}$ patients. This manoeuvre failed to influence the serum creatine kinase activity in these patients. To $\frac{-}{0}$ add to the difficulties, it has been shown that a⿳亠丷厂 remarkably high proportion of thyrotoxic patients $\widehat{\mathrm{D}}$ also have a myopathy (Grob, 1963) and the muscle from these patients has reduced creatine kinase ${ }^{\infty}$ activity compared with that of normal muscle.

Bertolini and Quarto di Palo (1956), having found $\overrightarrow{ }$ diminished phosphorylcreatine formation in cardiac. muscle of hypothyroid patients, concluded that thyroid hormone interfered with the reaction? mediated by creatine kinase. Askonas (1951) hadọ noted that thyroxine inhibits creatine kinase in vitro, possibly due to the binding of divalent ions, such aso magnesium, which are essential for the reaction to 0 proceed (Kuby, Noda, and Lardy, 1954). It might be expected, therefore, that abnormalities of muscular $\vec{c}$ contraction would occur in hypothyroidism. Myxo $=\mathbb{8}$ edema has occurred in cases of myotonia congenita栉 (Wade, 1957) and limb-girdle dystrophy (Comings,, 1962), but these cases are the exception rather than the rule.

The direct action of the thyroid hormone on the enzyme may be irrelevant, for considerable evidence has accumulated that the thyroid hormone is inti-o mately concerned with the uncoupling of phos phorylation at mitochondrial level (e.g., Hoch, 1962) The possibility that circulating thyroid hormone byo its inhibition was masking the true creatine kinase levels of normal serum has been considered. Mixingo equal quantities of normal (euthyroid) serum and $B$ that from a hypothyroid patient led to a reduction in creatine kinase activity proportional to the dilu? tion, and failed to correct the enzyme level to normal, which is evidence against the masking hypothesis.

If it is accepted that an enzyme leak from the tissues is the source of the increased enzyme activity in hypothyroidism, and this seems likely as severa $\widehat{\sigma}$ enzymes are affected, then it would be of interest to ascertain from which tissue the enzyme is released 5 Evidence of a disturbance of skeletal muscle activity in hypothyroidism has been quoted already. Cardiaç muscle may also be affected, as is evident from tha occurrence of pericardial effusions and ascites (Madenberg, Byfield, and Baker, 1954), and overf ascites was the presenting symptom of one of the patients in the series reported in this study. Deff Bakker, Sundermeyer, Wendt, Salhaney, Gudbjar离 nason, and Bing (1962), who carried out metabolic studies on a patient with Hashimoto's disease, were able to demonstrate a disturbance of myocardia metabolism.

Further evidence that the source of the increase 
serum enzyme activity in hypothyroidism comes from heart muscle was provided by creatine kinase assays on serum from patients suffering from hypothyroidism, myocardial infarction, and Duchenne muscular dystrophy which had been subjected to electrophoresis on cellulose acetate. The patterns in hypothyroidism and myocardial infarction were remarkably similar, about $45 \%$ of the total enzyme activity appearing in the $\beta$ and $\alpha_{2} \rightarrow \beta$ fractions, $20 \%$ in the albumin and immediately adjacent fractions, and $18 \%$ in the pre- $\gamma$ and $\gamma$-globulin fractions. In the dystrophy serum, $50 \%$ of the activity was in the latter fractions, $22 \%$ in the $\beta$ and $\alpha_{2} \rightarrow \beta$, and $8 \%$ in the albumin and adjacent fractions. Not only do these findings support the hypothesis that much of the increased serum enzyme activity observed in hypothyroidism arises from cardiac muscle, but also supports the evidence of Wood (1963a, 1963b) and Deul and van Breemen (1964) that multiple forms of the enzyme may exist, a situation analogous to that of lactate dehydrogenase, in which attempts have been made to exploit the varying isoenzyme patterns exhibited by different organs to assist in the differential diagnosis between conditions in which increased serum lactate dehydrogenase activity has been observed (e.g., Wilkinson, 1963).

Clinically, there are mental changes in hypothyroidism, and the bradycardia may be of central origin. Therefore, one cannot eliminate the possibility that cells of different organs may contribute to an increased serum enzyme activity.

In conclusion, one must ask whether the high serum activities, especially of creatine kinase, may provide valuable information to the clinician in cases of thyroid disease. Clearly, it is important to know of any condition in which abnormal enzyme levels are observed to avoid misleading interpretations being placed upon results obtained from serum enzyme assays. Hypothyroidism appears to be the only condition, other than muscular dystrophy, in which high levels of creatine kinase are sustained in the absence of specific treatment, so perhaps the assay is of potential value in the suspected hypothyroid patient. Although $90 \%$ of hypothyroid cases are likely to exhibit such high activities, the procedure, while more reliable than serum cholesterol estimations, is not as efficient as the tests with radioactive tracers or protein-bound iodine estimations, and it is in the mildly hypothyroid case, in which the greatest doubt exists in the clinician's mind, that the enzyme test is most likely to fail. In these circumstances it is unlikely, in the author's view, that assay of serum creatine kinase activity will find a place in the investigation of diseases of the thyroid gland.

My thanks are due to the Directors of the Department of Clinical Pathology, Guy's Hospital, S.E.1, Dr. W. H. H. Merivale, and of the Group Laboratory, Lewisham Hospital, S.E.13, then Dr. E. N. Allott, in whose departments the work was carried out, the clinicians of the two hospitals for access to their patients, and Dr. H. Lehmann, of Addenbrooke's Hospital, Cambridge, for their help and support in this work.

\section{REFERENCES}

Askonas, B. A. (1951). Nature (Lond.), 167, 933.

Bertolini, A. M., and Quarto di Palo, F. M. (1956). Acta med. scand., $153,329$.

,-- (1958). Acta vitaminol., 12, 3.

Bruns, F. (1954). Biochem. Z., 325, 156.

Comings, D. E. (1962). Arch. intern. Med., 109, 724.

Della Santa, L. (1962). Minerva pediat., 14, 136.

(1963). Panminerva med., 5, 69.

Den Bakker, P. B., Sundermeyer, J. F., Wendt, V. E., Salhaney, M., Gudbjarnason, S., and Bing, R. J. (1962). Amer. J. Med., 32, 822.

Deul, D. H., and van Breemen, J. F. L. (1964). Clin. chim. Acta, 10, 276.

Ebashi, S., Toyokura, Y., Momoi, H., and Sugita, H. (1959). J. Biochem. (Tokyo), 46, 103.

Ennor, A. H., and Rosenberg, H. (1954). Biochem. J., 57, 203.

Graig, F. A., and Ross, G. (1963). Metabolism, 12, 57.

Griffiths, P. D. (1963). Lancet, 1, 894.

- (1965). Guy's Hosp. Rep., in the press.

Grob, D. (1963). N.Y. State J. Med., 63, 218.

Hoch, F. L. (1962). Physiol. Rev., 42, 605.

Kuby, S. A., Noda, L., and Lardy, H. A. (1954). J. biol. Chem., 210, 65.

Lieberthal, A. S., Benson, S. G., and Klitgaard, H. M. (1963). J. clin. Endocr., 23, 211.

Madenberg, F., Byfield, G. V., and Baker, L. A. (1954). Arch. intern. Med., 93, 787.

Reitman, S., and Frankel, S. (1957). Amer. J. clin. Path., 28, 56.

Saito, M., Hibi, I., Kawazura, M., and Fukuyama, Y. (1963). Lancet, $2,252$.

Sibley, J. A., and Fleisher, G. A. (1954). Proc. Mayo Clin., 29, 591. Solvonuk, P. F., McRae, S. C., and Collier, H. B. (1956). Canad. J. Biochem. Physiol., 34, 481.

Vogliazzo, U., Borney, G., and Gheis, F. (1960a). Minerva med., 51, 1966.

, Viale, G., and Borney, G. (1960b). Ibid., 51, 1719.

Wade, A. F. (1957). Brit. med. J., 1, 1223.

Wilkinson, J. H. (1963). Proc. roy. Soc. Med., 56, 177.

Wood, T. (1963a). Biochem. J., 87, 543.

(1963b). Ibid., 89, 210. 